\title{
Deiodinases: implications of the local control of thyroid hormone action
}

\author{
Antonio C. Bianco and Brian W. Kim
}

Thyroid Section, Division of Endocrinology, Diabetes and Hypertension, Department of Medicine, Brigham and Women's Hospital and Harvard Medical School, Boston, Massachusetts, USA.

\begin{abstract}
The deiodinases activate or inactivate thyroid hormone, and their importance in thyroid hormone homeostasis has become increasingly clear with the availability of deiodinase-deficient animals. At the same time, heightened interest in the field has been generated following the discovery that the type 2 deiodinase can be an important component in both the Hedgehog signaling pathway and the G protein-coupled bile acid receptor 1-mediated (GPBAR1-mediated) signaling cascade. The discovery of these new roles for the deiodinases indicates that tissuespecific deiodination plays a much broader role than once thought, extending into the realms of developmental biology and metabolism.
\end{abstract}

Thyroid hormone 3,5,3'-triiodothyronine (T3) and its precursor thyroxine (T4) are iodinated compounds known to influence gene expression in virtually every vertebrate tissue. Fundamentally, thyroid hormone signaling results from the interaction of nuclear thyroid hormone receptors (TRs) with specific target gene promoters, a process that can either enhance or repress transcription. This process is modulated via binding of thyroid hormone, the ligand, to the TRs, which results in alterations in the composition of the transcriptional complex (1-3). Signaling through this pathway is, of course, sensitive to changes in serum thyroid hormone concentrations, and the consequences of deranged thyroid function, as seen in patients with Graves hyperthyroidism or Hashimoto thyroiditis, have been recognized for over 100 years. The modern paradigm of thyroid hormone action also recognizes that thyroid hormone signaling in individual tissues can change even as serum hormone concentrations remain normal, thanks to local activation or inactivation of thyroid hormone (4-6). The underlying mechanism of these phenomena is deiodination.

The iodothyronine deiodinases types I, II, and III (D1, D2, and $\mathrm{D} 3$, respectively) regulate the activity of thyroid hormone via removal of specific iodine moieties from the precursor molecule T4 (Figures 1 and 2). These 3 enzymes constitute a group of dimeric integral membrane thioredoxin fold-containing proteins $(7-10)$ that can activate or inactivate thyroid hormone, depending on whether they act on the phenolic or tyrosil rings of the iodothyronines, respectively (11). D2 generates the active form of thyroid hormone T3 via deiodination of T4. In contrast, D3 inactivates T3 and, to a lesser extent, prevents T4 from being activated. Finally, D1 is a kinetically inefficient enzyme that activates or inactivates $\mathrm{T} 4$ on an equimolar basis, and its role in health remains to be clarified. In general, a given cell type will

Nonstandard abbreviations used: D1, type I iodothyronine deiodinase; Dio3, type III iodothyronine deiodinase; D1KO mice, Dio1-knockout mice; GPBAR1, G protein-coupled bile acid receptor 1; PTU, propylthiouracil; T3, 3,5,3'-triiodothyronine; T4, thyroxine; TR, thyroid hormone receptor; TRH, TSH-releasing hormone; TSH, thyroid-stimulating hormone; UCP-1, uncoupling protein 1; VDU, von Hippel-Lindau protein-interacting deubiquitinating enzyme; WSB-1, WD repeat and SOCS box-containing 1 .

Conflict of interest: The authors have declared that no conflict of interest exists. Citation for this article: J. Clin. Invest. 116:2571-2579 (2006). doi:10.1172/JCI29812. express only 1 type of deiodinase at a given time, though some tissues express none, and all 3 types of activity have been measured in the pituitary gland (Table 1 ).

The activity of the deiodinases can substantially alter thyroid hormone signaling in a given cell (5). While the total concentration of T4 exceeds that of T3 by 2 orders of magnitude, T4 is tightly bound to carrier proteins, and the free concentrations of T4 and T3 are quite similar. Both enter the cell via transporters, including the monocarboxylate transporter 8 and the organic anion transporting polypeptide C1 (12). Once inside the cell, T4 can be activated via conversion to T3 by the D2 pathway, such that the cytoplasmic pool of T3 includes both T3 from the plasma and T3 generated by D2 (Figure 3). Alternatively, D3 acts at the plasma membrane to decrease local T3 concentrations (Figure 4). Thus, the deiodinases are critical determinants of the cytoplasmic $\mathrm{T} 3$ pool and therefore modulate nuclear $\mathrm{T} 3$ concentration and $\mathrm{TR}$ saturation (13). In normal rats, the D2 pathway is responsible for about half of the nuclear T3 content in the brain, pituitary gland, and brown adipose tissue $(14,15)$.

Abnormalities in deiodinase activity are important in a number of clinical settings. The best-known example is critical illness, during which changes in deiodinase activities are linked to complex alterations in thyroid hormone metabolism (16). Another common setting is patients being treated with amiodarone, an antiarrhythmic drug well known to alter thyroid function tests via both direct actions on the thyroid and inhibition of T4 activation (17). While rare, vascular tumors with high D3 activity have been shown to cause severe hypothyroidism in both adults and children $(18,19)$. Increased D3 activity as a general mechanism may have much broader clinical relevance; as fetoplacental and uterine D3 activity increase dramatically during pregnancy $(20,21)$, this activity may be the cause of increased L-thyroxine requirements in pregnant patients with hypothyroidism (22). Individuals with genetic alterations in the deiodinases have not yet been identified, though the clinical implications of several polymorphisms are under investigation (23-27). Understanding the signaling pathways these enzymes are involved with could have therapeutic utility for all of these clinical settings. However, the real excitement in this field stems from the discoveries that deiodinases can participate in both the bile acid and Hedgehog signaling cascades (Figure 4) $(28,29)$. 


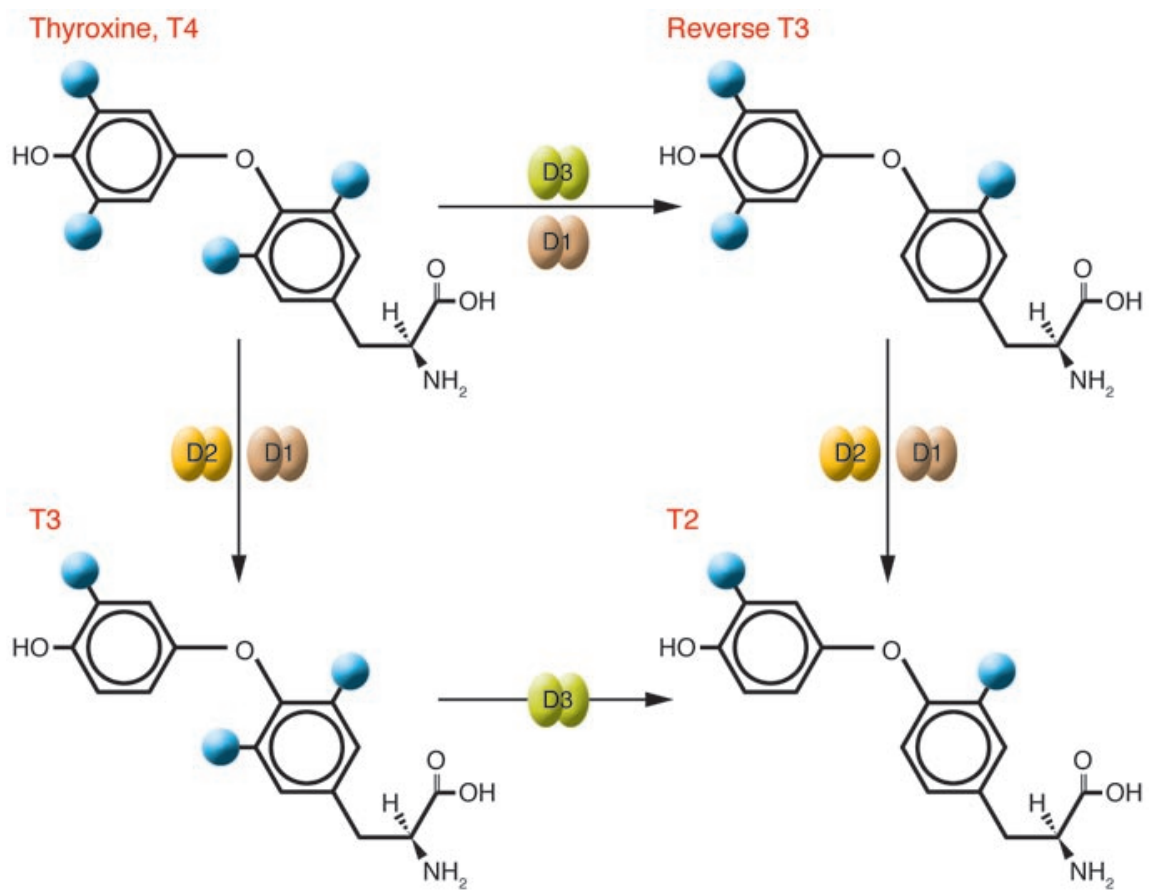

\section{Figure 1}

Basic deiodinase reactions. The reactions catalyzed by the deiodinases remove iodine moieties (blue spheres) from the phenolic (outer rings) or tyrosil (inner rings) rings of the iodothyronines. These pathways can activate T4 by transforming it into T3 (via D1 or D2) or prevent it from being activated by converting it to the metabolically inactive form, reverse T3 (via D1 or D3). T2 is an inactive product common to both pathways that is rapidly metabolized by further deiodination.
As a result of this linkage, novel roles for these enzymes in the realms of metabolic control and developmental biology have become apparent.

\section{Deiodinases in thyroid homeostasis}

Serum T3 levels are relatively constant in healthy subjects, a finding that is not surprising considering that $\mathrm{T} 3$ is such a pleiotropic molecule. The deiodinase signaling pathways in peripheral tissues constitute a major determinant of plasma T3 level, since all T3 generated in the cytoplasm eventually exits the cell, unless of course it is metabolized. In fact, extrathyroidal pathways have been estimated to contribute about $80 \%$ of T3 produced daily in healthy subjects (30). The D2 pathway, rather than the D1 pathway, is thought to be the major source of extrathyroidal $\mathrm{T} 3$ production in humans based on a number of prior clinical studies $(31,32)$. This conclusion is supported by in vitro modeling data, in which $\mathrm{T} 3$ production via either the D1 or D2 pathways in the same cell types was compared at substrate concentrations spanning the hypothyroid to thyrotoxic range (33). In contrast, D1 activity is increased in patients with hyperthyroidism so that this pathway becomes the predominant extrathyroidal source of T3 (34). This D1 predominance underlies the rapid fall in serum T3 concentrations that occurs in patients with hyperthyroidism who are treated with propylthiouracil (PTU), an antithyroid drug that selectively inhibits D1mediated $\mathrm{T} 3$ production. The D3 pathway is recognized as being the predominant means for clearance of plasma T3. A dramatic example of the potency of the D3 pathway in determining serum $\mathrm{T} 3$ concentrations is shown in the syndrome of consumptive hypothyroidism, in which $\mathrm{T} 4$ and $\mathrm{T} 3$ clearance rates are greatly accelerated because of the presence of large infantile hepatic hemangiomas with high levels of D3 activity (Table 1) (18).

The actions of the deiodinases are integrated and thus promote the maintenance of serum T3 concentrations. Fluctuations in serum T4 and T3 concentrations lead to homeostatic, reciprocal changes in the activity of D2 and D3 (5). As serum T3 concentrations increase, expression of type III iodothyronine deiodinase (Dio3), which encodes D3, is upregulated, increasing T3 clearance, while expression of Dio2, which encodes D2, is modestly downregulated, decreasing T3 production. Conversely, if serum T3 concentrations were to fall, downregulation of the D3 pathway would decrease the clearance of T3. The homeostatic role of D1 is less intuitive, as Dio1 is T3 responsive (35). Given that D1 can deiodinate the phenolic and tyrosil rings of T4 with equal facility, D1 in effect activates only 1 of every 2 molecules of T4. Thus, D1's homeostatic function may be to siphon T4 away from the D2 pathway, therefore providing some degree of protection against the development of hyperthyroidism when serum T4 concentrations increase (Table 1).

Another D2-mediated regulatory mechanism relevant to T3 homeostasis is covalent attachment to the approximately $8-\mathrm{kDa}$ protein ubiquitin, which inactivates the enzyme (36). Like other ubiquitinated proteins, D2 is degraded in the large protease complexes known as proteasomes (37), but D2 can also be reactivated by von Hippel-Lindau protein-interacting deubiquitinating enzymes 1 and 2 (VDU1 and VDU2, respectively) (Figure 3) (38). D2 ubiquitination accelerates in proportion to T4 concentration, creating a feedback loop controlling D2-mediated T3 production $(36,37)$. Therefore, if serum T4 concentrations fall, activation of the D2 pathway compensates, at least in part, for the lowered substrate concentration by increasing the relative proportion of T4 converted to T3 (Table 1).

\section{Insights from deiodinase-deficient mouse models}

Insight as to the importance of the deiodinase-based homeostatic mechanisms for the maintenance of serum T3 concentrations has been gained from studies of genetically modified mice (Table 2) (39). Four mouse models have been described with varying deficiencies in the activating deiodinases: mice with targeted disruption of Dio1 (D1KO mice) (40); mice with targeted disrup- 


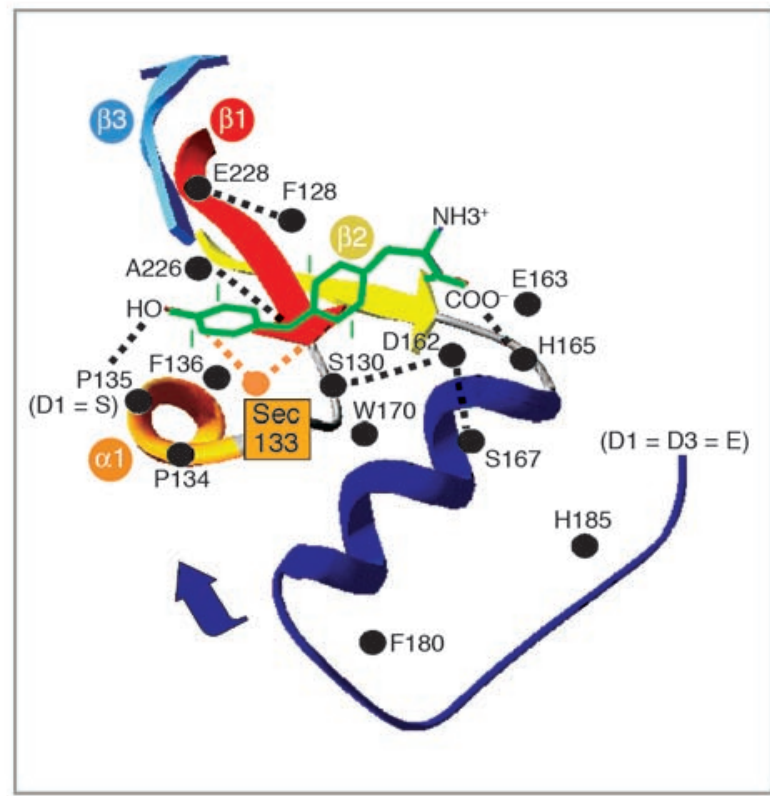

Active center

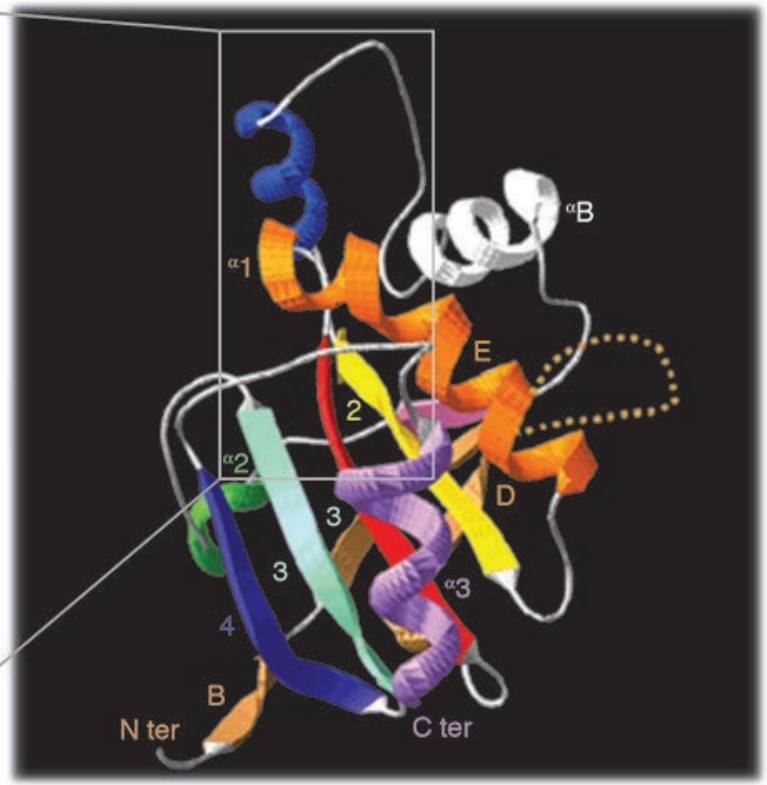

A 3D model of D2

\section{Figure 2}

Deiodinases. While the deiodinases have not yet been crystallized, protein modeling indicates that they share a common general structure composed of a single aminoterminal-anchoring segment, a short hinge region, and a thioredoxin fold-containing globular domain (9). A 3D model of the D2 globular domain is shown on the right. Letters and numbers shown indicate different $\beta$ sheets and $\alpha$-helices as previously reported (9). The orange dotted loop indicates the D2-specific segment that mediates interaction with the E3-ubiquitin ligase WSB-1 (28). The inset illustrates the active center, which contains the rare amino acid selenocysteine $(\mathrm{Sec})$, which is critical for nucleophilic attack during the deiodination reaction. The residues that putatively interact with the T4 molecule (green) are also shown. Position 135, which in D2 and D3 is occupied by proline, is critical for enzyme kinetics. D2 and D3 have high affinity for their substrates and are not sensitive to inhibition by PTU. Replacement with serine, which is naturally found in D1, turns both D2 and D3 into low affinity and PTU-sensitive enzymes (9). C ter, $\mathrm{C}$ terminus; $\mathrm{N}$ ter, $\mathrm{N}$ terminus. Figure modified with permission from the Journal of Biological Chemistry (9) and Nature Cell Biology (28).

tion of the Dio2 gene (D2KO mice) (41); $\mathrm{C} 3 \mathrm{H}$ mice, which have genetically low levels of D1 $(42,43)$; and D2 KO mice backcrossed into a $\mathrm{C} 3 \mathrm{H}$ background (C3H/D2KO mice) (44). Remarkably, each of these animals has a normal serum $\mathrm{T} 3$ concentration and an increased serum T4 concentration. Clearly, potent compensatory mechanisms for maintaining serum T3 must exist, but what are they? One component of this response must be that the high serum $\mathrm{T} 4$ concentrations provide sufficient substrate to compensate for the partial losses of activating deiodinases. The elevations in serum $\mathrm{T} 4$ concentration may result from increased thyroidal secretion and/or decreased clearance, but in either case it is fascinating that the hypothalamic-pituitary-thyroid axis could be wired such that adjustments in serum $\mathrm{T} 4$ concentrations are made in order to maintain serum T3 concentrations.

Another likely component of the T3-maintenance response in these animal models could be increased thyroidal T3 secretion due to increased thyroid-stimulating hormone (TSH) levels. $\mathrm{TSH}$ is released from thyrotroph cells in the anterior pituitary gland, and its role is to stimulate virtually every aspect of thyroid hormone biosynthesis and secretion. In the absence of TSH, thyroidal activity falls and secondary hypothyroidism ensues. In fact, both the D2 KO and $\mathrm{C} 3 \mathrm{H} / \mathrm{D} 2 \mathrm{KO}$ models feature an elevation in serum TSH concentrations. It must be noted that serum $\mathrm{TSH}$ concentrations are normal in $\mathrm{C} 3 \mathrm{H}$ and $\mathrm{D} 1 \mathrm{KO}$ mice in spite of sizeable elevations in serum T4. In these cases, the D2 pathway may play a more prominent role in the maintenance of serum T3 concentration.
TSH release is under negative feedback regulation by thyroid hormone at the pituitary and hypothalamic levels, the latter involving suppression of TSH-releasing hormone (TRH) from paraventricular neurons. Given that $\mathrm{T} 3$ is the active form of thyroid hormone, it is not surprising that a negative feedback relationship exists between plasma T3 and TSH release. However, the fact that TSH release is also suppressed by plasma T4 may seem surprising, given that the latter is thought to be a prohormone (45). Mechanistically, fluctuations in serum T4 are transduced in pituitary thyrotrophs by the D2 pathway (46). The fact that the set point for TSH secretion depends on both serum T3 and T3 generated by D2 in the thyrotrophs can explain why TSH rises during iodine deficiency and mild hypothyroidism, situations in which serum $\mathrm{T} 4$ concentrations fall before there is any fall in serum T3 concentrations $(14,47)$.

Given the importance of thyrotroph D2 in TSH regulation, one would predict that D2KO animals would have an increased set point for TSH secretion, and indeed, serum TSH concentrations are 2 times higher than in normal mice (41). Given that $\mathrm{D} 1$ is not expressed in thyrotrophs, the reasons that D1KO mice have normal TSH concentrations in the face of high serum T4 and normal serum T3 concentrations are less clear, since this combination might be expected to suppress TSH release. One hypothesis is that the feedback effect of T4 on TSH release varies depending on serum T4 concentration, becoming less effective as serum T4 concentrations increase (Figure 3). Such a relationship has in fact been demonstrated in cultured wild-type thyro- 
Table 1

Human iodothyronine selenodeiodinases

Parameter

Biochemical properties

Molecular weight of monomer (Da)

Preferred substrates (position)

$K_{\mathrm{m}}$ (apparent) (M)

Half-life

Subcellular location

\section{Susceptibility to inhibitors}

PTU

Amiodarone/metabolites

Tissues with high activity

Induction

Repression

Physiological role

Role in diseases
Liver, kidney

$\uparrow \uparrow$

T3

Clearance of rT3 and T3S

D1

$$
\begin{gathered}
29,000 \\
\text { rT3 }\left(5^{\prime}\right), \text { T3S (5) } \\
10^{-7}, 10^{-6} \\
\text { Several hours }
\end{gathered}
$$

High

High

Fasting, illness

Main source of plasma T3

in hyperthyroid patients
D2

30,500

T4, rT3

$10^{-9}$

Approximately 20 minutes

Endoplasmic reticulum

Very low

CNS, pituitary, brown adipose tissue, placenta

\section{$\downarrow \downarrow \downarrow$ (Ubiquitination)}

Cold exposure, overfeeding, catecholamines, bile acids, CAMP, VDU1/VDU2, deubiquitination

T3, Hedgehog family T4 via WSB-1 ubiquitination

Thermogenesis, development, provides intracellular T3, major source of plasma T3

?
D3

31,500

T3, T4

$10^{-9}$

Several hours

Plasma membrane

Very low

?

Placenta, CNS, hemangiomas

$\uparrow \uparrow$

$?$

Tissue injury T3, TGF- $\beta$, aFGF, bFGF, EGF,

PDGF, ERK activators

Growth hormone, glucocorticoids

Development, clearance of $\mathrm{T} 3$ and T4, avoidance of intracellular T3 production

Consumptive hypothyroidism, increased T4/T3 clearance in pregnant women, illness

Detailed deiodinase properties can be obtained in previously published reviews $(4-7,11)$. Up and down arrows indicate increases and decreases, respectively; the number of arrows corresponds with the intensity of the change. aFGF, acidic FGF; bFGF, basic FGF; rT3, reverse T3; T3S, triiodothyronine sulfate.

trophs, in which D2-mediated T3 production increases approximately 5 -fold when free $\mathrm{T} 4$ in the medium is elevated from hypothyroid to euthyroid concentrations (from 1 to $20 \mathrm{pM}$ ) but only increases approximately 2 -fold during the transition into the hyperthyroid range (from 20 to $400 \mathrm{pM}$ ) (46). Given that these concentrations of $\mathrm{T} 4$ are well below the $K_{\mathrm{m}}$ (T4) for $\mathrm{D} 2$, which is approximately $1 \mathrm{nM}$, the likely explanation for the asymptotic relationship between $\mathrm{T} 4$ substrate and $\mathrm{T} 3$ production is ubiquitination of $\mathrm{D} 2$, which accelerates as serum $\mathrm{T} 4$ concentrations increase.

The knowledge gained from these animal models of deiodinase deficiency could ultimately help explain the phenotype of affected individuals in 2 families with inherited mutations in the gene for the selenocysteine insertion sequence-binding protein 2 (SBP-2), a protein important for the synthesis of selenoproteins, including the deiodinases (48). Deficiencies in all 3 deiodinases would be predicted to occur in these subjects, and indeed D2 activity is low in cultured fibroblasts. The functional characterization of these patients with respect to the deiodinases is not complete, and thus it is premature to discuss the mechanisms that underlie their thyroid phenotype. Nevertheless, it is striking that serum TSH concentrations and serum T4 concentrations are both high in affected individuals, reminiscent of the mouse models of activating deiodinase deficiency (48).

\section{Thyroid hormone homeostasis in illness}

Life-threatening trauma, major surgery, and critical illness are associated with a well-known pattern of decreased pituitary-thyroid function, sometimes referred to as the low T3 syndrome. These patients have low serum T3 concentrations, which are inversely related to the severity of their illness, and eventually develop low serum T4 and TSH concentrations (49-51). Whether these changes represent physiologic compensation for the illness or a pathological state is a long-standing controversy (52), but the fact that the changes can occur in a matter of hours indicates a profound alteration of thyroid economy.

It is believed that decreased extrathyroidal conversion of T4 to $\mathrm{T} 3$ is a primary mechanism underlying the low T3 syndrome. A decrease in the activity of the D1 pathway has been observed in a number of animal models (53). However, it must be kept in mind 


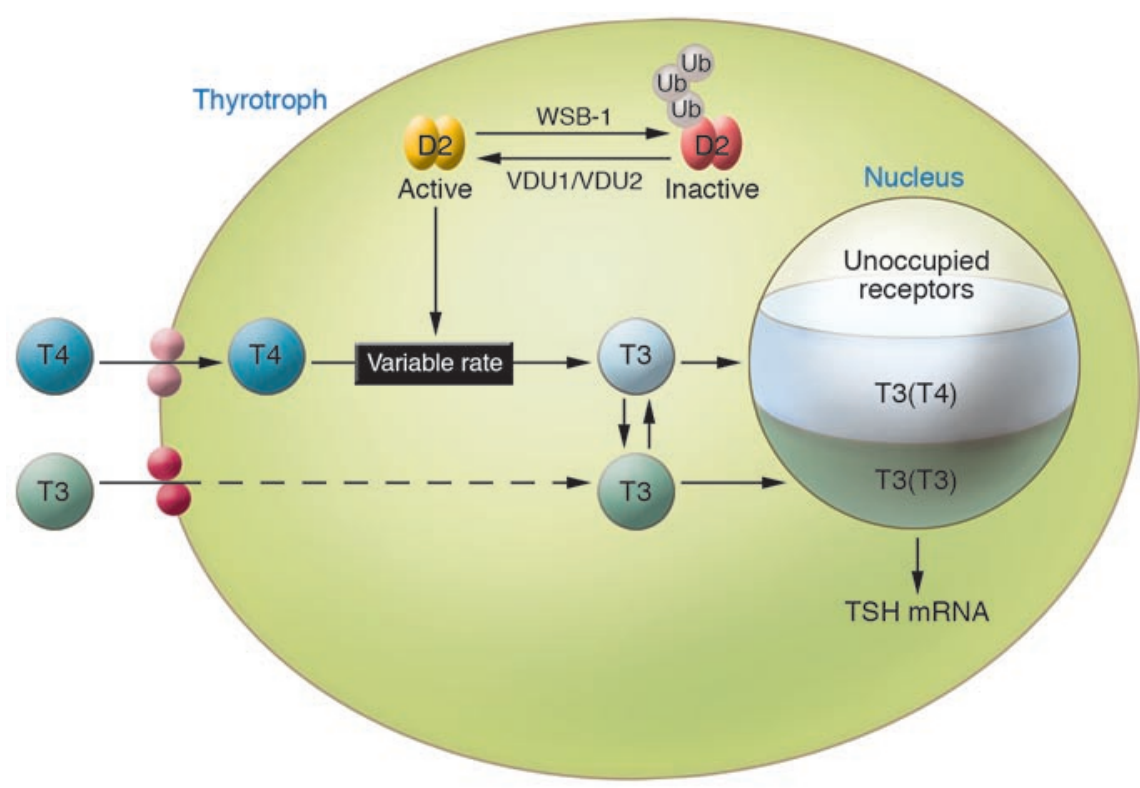

Figure 3

Role of D2 in TSH feedback. In the thyrotroph, TSH is subject to negative feedback by T3, which arrives in the nucleus from 2 distinct sources: plasma T3, illustrated as T3(T3); and plasma T4, which is then converted to T3 intracellularly via the D2 pathway, represented as T3(T4). The schematic includes the plasma membrane, which contains thyroid hormone transporters (indicated by the pink and red circles); the cytoplasm, containing the enzymes involved in thyroid hormone metabolism; and the nucleus, containing the TRs. D2 is represented in active form (yellow) and inactive form (red). Transition between active and inactive D2 is via ubiquitination and deubiquitination, reactions that are catalyzed by WSB-1 and VDU1/VDU2, respectively. As a result of ubiquitination, D2-mediated T4-to-T3 conversion occurs at variable rates, decreasing as serum T4 concentration increases (46). Ultimately, these processes determine nuclear TR saturation, which includes contributions from both T3(T3) and T3(T4) as indicated, with only a minor fraction of the TRs being unoccupied under normal conditions. Ub, Ubiquitin. Figure modified with permission from Endocrine Reviews (14).

that Dio1 is a gene highly responsive to T3, and thus the low D1 activities measured in these animals could be an effect of rather than a cause of the low T3 syndrome (54). Furthermore, the D2 pathway rather than the D1 pathway is the predominant source of serum T3 in humans, and so these D1 data may not directly apply in patients. In fact, it has been documented that skeletal muscle samples from critically ill patients obtained within minutes of death do not have D2 activity. Remarkably, these patients exhibited ectopic induction of D3 activity in liver and skeletal muscle samples, suggesting that increased thyroid hormone catabolism may be an additional component of the syndrome (55).

While changes in peripheral deiodination may be necessary for the pathogenesis of the syndrome, they are probably not sufficient to cause it. Given the remarkable capacity of the hypothalamic-pituitary-thyroid axis to compensate for decreases in $\mathrm{T} 3$ production in peripheral tissues, as demonstrated in the deiodinase-deficient mice, central hypothyroidism must also be part of the syndrome (56). TSH secretion is decreased in critically ill subjects, and continuous infusion of TRH has been shown to strikingly increase serum T4 and T3 concentrations (57). The molecular determinants of central hypothyroidism in these patients are not well characterized. While dopamine and glucocorticoids play a suppressive role with respect to TSH (58), leptin administration leads to increases in serum TSH, T4, and
T3 concentrations in fasting rats (59) and humans (60). Another pathway that could be involved in the suppression of TSH secretion is the NF- $\mathrm{KB}$ cascade, which upregulates D2 expression in the medial basal hypothalamus of rats following LPS injection $(61,62)$, though it remains speculative whether this induction of D2 leads to local thyrotoxicosis and thus decreased TRH secretion. Ultimately, it seems that the low T3 syndrome does involve changes in peripheral deiodination but also requires a form of central hypothyroidism in which the peripheral alterations in thyroid hormone metabolism are not compensated as they would be in healthy subjects or in the mice with deiodinase deficiencies.

\section{D2 control of energy expenditure}

While deiodinase activities change in homeostatic ways in response to fluctuations in serum concentrations of $\mathrm{T} 3$ and $\mathrm{T} 4$, these enzymes are also directly regulated via a wide variety of intracellular signals not obviously related to thyroid hormones. The first evidence that primary changes in deiodinase activity elicit downstream effects in response to nonthyroidal signals came from studies of brown adipose tissue in rodents. This tissue is the major site of adaptive thermogenesis in rodents, with heat being generated as a result of the actions of uncoupling protein 1 (UCP-1) (63). Cold-induced thermogenesis in brown adipose tissue has been shown to depend upon the cyclic AMP-mediated acceleration of D2-catalyzed T3 production (64), which in turn leads to the induction of T3-responsive thermogenic genes, including UCP-1 (Figure 4). In spite of the D2-mediated increase in nuclear T3 levels (65), serum T3 concentrations do not change, indicating that D2 has a tissue-specific metabolic action. Without this action, brown adipose tissue thermogenesis is impaired, and $\mathrm{D} 2 \mathrm{KO}$ mice survive in the cold only by shivering, a behavior not normally seen in small mammals $(66,67)$.

That the action of D2 has relevance for metabolism beyond its role in cold-induced thermogenesis was recently established with the discovery that bile acids can confer resistance to diet-induced obesity in mice via upregulation of D2 expression in brown adipose tissue (29). In this tissue, binding of bile acids to the plasma membrane $G$ protein-coupled bile acid receptor 1 (Gpbar1, also known as Tgr5) triggers an increase in cyclic AMP formation and, subsequently, D2 expression. In normal mice fed a high-fat diet supplemented with bile acids, oxygen consumption increased and the mice did not gain weight or become as insulin resistant as mice fed the high-fat diet alone. However, this effect is lost in D2KO mice. It is noteworthy that D2 is overexpressed in 2 other rodent models of resistance to diet-induced obesity. Ucp-1-knockout mice are paradoxically lean (68) and have ectopic expression of D2 in their white fat while double liver X receptor (LXR) knockout mice 


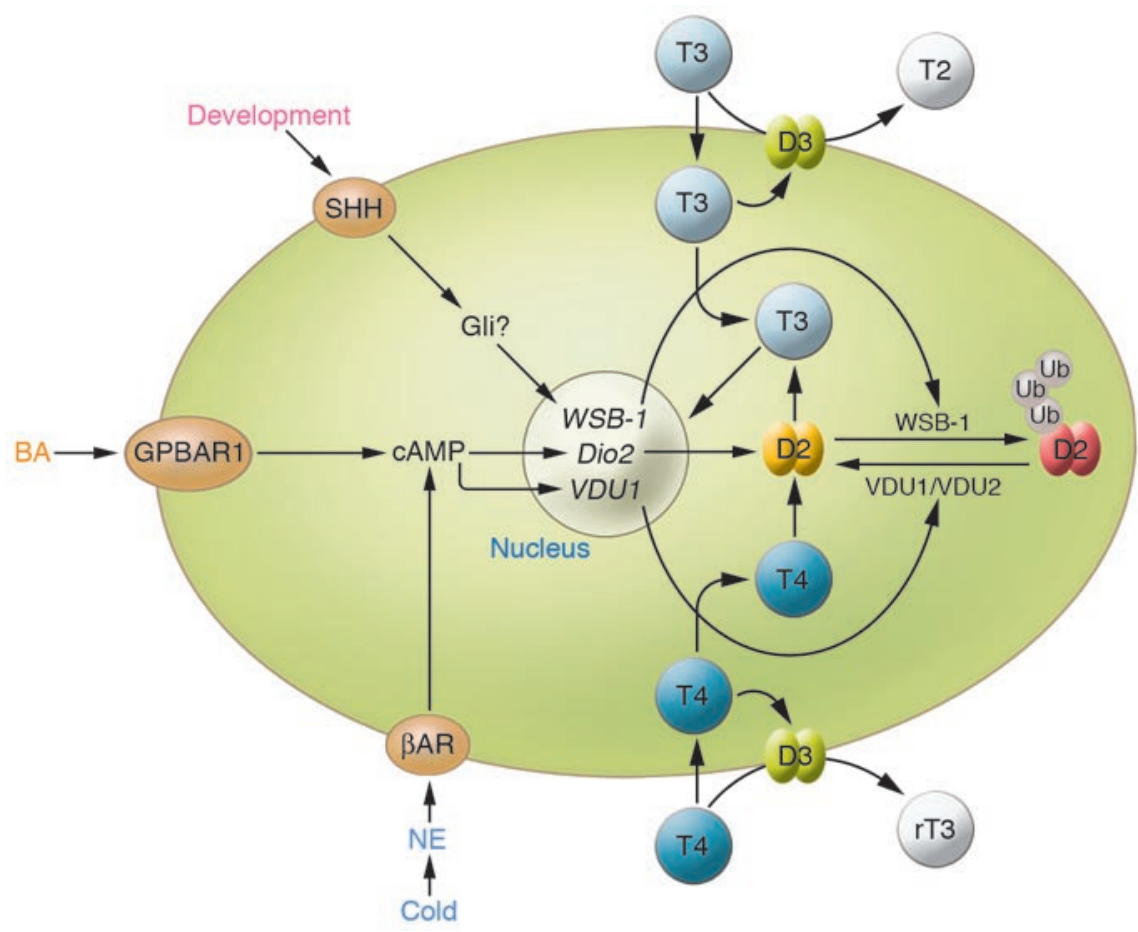

\section{Figure 4}

Pathways regulating D2 expression and thyroid hormone signaling. In D2-expressing cells, such as brown adipocytes, stimulation of D2 expression increases local T3 production, resulting in increased saturation of T3 receptors. This increase can be mediated by norepinephrine (NE) stimulation of $\beta$-adrenergic receptors ( $\beta A R s)$, such as occurs during cold stimulation, or by bile acid-mediated (BA-mediated) stimulation of GPBAR1 (also known a TGR5). Both of these pathways activate CAMP production and stimulate Dio2 transcription. In brown fat, cAMP also promotes VDU1 expression, amplifying D2 induction via deubiquitination. Other signaling pathways can decrease D2 activity, resulting in relative local hypothyroidism. For example, the Hedgehog cascade decreases D2 activity by promoting WSB-1 expression and thus D2 ubiquitination, presumably via the Gli cascade. rT3, reverse T3; SHH, sonic hedgehog. express D2 ectopically in the liver (69). If the ectopic expression of D2 in these animals results in tissue-specific thyrotoxicosis, as is suggested by gene expression profiling in the case of the LXR double-knockout mice, this would certainly support the concept that the D2 signaling pathway increases energy expenditure.

It has been assumed that the D2 pathway is more important for thermogenesis during infancy than in adulthood, based on the observation that the mass of brown adipose tissue in humans peaks at the time of birth (70-72). However, adults retain enough brown adipocytes such that brown fat mass increases in high catecholamine states, as evidenced in patients with pheochromocytoma (73). These neuroendocrine tumors secrete catecholamines, which drive brown fat growth via increases in adipocyte cyclic AMP production. In fact, even normal adults may have more brown adipose than once thought, as studies utilizing 2-deoxy-2-[F-18]fluoro-D-glucose (FDG) in PET scans have indicated the presence of brown adipose in the neck $(74,75)$. While histologic correlation for these supracla- vicular areas of FDG uptake remains to be performed, it has been demonstrated that this uptake can be reduced or eliminated when subjects are studied in a setting where cold stress is eliminated (76).

Another potential site where the bile acid/GPBAR1/D2 pathway may affect energy expenditure in adults is in skeletal muscle, and the pathway has been shown to be operant in human skeletal myocytes in culture (29).

While the link between the D2 pathway and energy expenditure seems clear, it must be remembered that the identities of the T3responsive genes that most directly lead to increases in energy expenditure remain to be determined. Identifying these critical genes is an important goal since thyroid hormone is one of the few known truly potent stimulators of the metabolic rate; indeed, energy expenditure is several-fold higher in hyperthyroid as compared with hypothyroid patients (77). The cellular mechanisms by which T3 increases energy expenditure are thought to include increased mitochondrial uncoupling, as this effect has been demonstrated in both the skeletal mus-

\section{Table 2}

Major phenotypic characteristics of deiodinase-deficient mice as compared with wild-type mice

\begin{tabular}{|c|c|c|c|c|c|}
\hline Parameter & D1K0 & D2KO & D3KO & $\mathrm{C} 3 \mathrm{H}$ & $\mathrm{C} 3 \mathrm{H} / \mathrm{D} 2$ \\
\hline \multicolumn{6}{|l|}{ Thyroid function tests } \\
\hline $\begin{array}{l}\text { Serum T4 level } \\
\text { Serum T3 level } \\
\text { Serum TSH level }\end{array}$ & $\begin{array}{l}\text { Increased } \\
\text { Normal } \\
\text { Normal }\end{array}$ & $\begin{array}{l}\text { Increased } \\
\text { Normal } \\
\text { Increased }\end{array}$ & $\begin{array}{l}\text { Increased } \\
\text { Decreased } \\
\text { Normal }\end{array}$ & $\begin{array}{l}\text { Increased } \\
\text { Normal } \\
\text { Normal }\end{array}$ & $\begin{array}{l}\text { Increased } \\
\text { Normal } \\
\text { Increased }\end{array}$ \\
\hline \multicolumn{6}{|l|}{ Phenotype } \\
\hline $\begin{array}{l}\text { Systemic } \\
\text { Tissue specific }\end{array}$ & $\begin{array}{l}\text { Euthyroid } \\
\text { Not reported }\end{array}$ & $\begin{array}{c}\text { Euthyroid } \\
\text { Mild cold intolerance, } \\
\text { hearing impairment }\end{array}$ & $\begin{array}{c}\text { Hypothyroid } \\
\text { Central hypothyroidism }\end{array}$ & $\begin{array}{l}\text { Euthyroid } \\
\text { Not reported }\end{array}$ & $\begin{array}{l}\text { Euthyroid } \\
\text { Not reported }\end{array}$ \\
\hline Reproductive capacity & Normal & Normal & Impaired & Normal & Normal \\
\hline
\end{tabular}

Table was compiled based on data from previous reports $(40,41,66,90,92)$. 
cle of mildly thyrotoxic human volunteers (78) and in hepatocytes of thyrotoxic rats (79). However, in neither case has a clear link to uncoupling proteins been established. Another general mechanism by which T3 has been reported to increase energy expenditure is via acceleration of the turnover of ATP-utilizing enzymes. Several candidate genes have been implicated, including those coding for $\mathrm{Na}^{+} / \mathrm{K}^{+}$ATPase $(80,81)$ and sarcoplasmic endoplasmic reticulum $\mathrm{Ca}^{2+}$ ATPase $(82,83)$, among others (84-86).

\section{Local control of thyroid hormone action during development}

Thyroid hormone has well-known important developmental functions $(87,88)$. Serum thyroid hormone concentrations are generally low during development, and the contrast between serum and tissue T 3 content afforded by the deiodinases is thus particularly critical for developing structures $(39,87)$. Signaling via thyroid hormone is tightly regulated both spatially and temporally via the expression pattern of deiodinases. The thyroid hormone-inactivating D3 pathway is highly stimulated during development, with a tissue distribution much broader than that in adults. The expression pattern of D3 limits thyroid hormone signaling locally in developing structures and also systemically by lowering serum T3 concentrations. In some tissues, the timing of D3 expression has been shown to be critical, e.g., T3-induced proliferation of retinal ciliary marginal zone cells in Xenopus laevis occurs preferentially in ventral cells because dorsal cells express D3 (89). This spatial asymmetry allows for proper rotation of the retina during development. Proper D3 expression is also critical for the development of the hypothalamic-pituitary-thyroid axis itself, as evidenced by the observations that mice with targeted disruption of the Dio3 gene (D3KO mice) have central hypothyroidism after having high serum $\mathrm{T} 3$ concentrations late in embryonic life and for the first 10 days after birth (90). The regulatory mechanisms underlying the developmental expression of Dio3 remain a subject of active interest; notably, the morphogen TGF- $\beta$ has been found to be a potent stimulant of Dio3 transcription (91).

The expression of Dio2 is more limited during development. Bursts of D2 activity occur in some tissues, allowing for increased thyroid hormone signaling in both spatially and temporally specific patterns. For example, there is a 3-day peak of Dio2 expression and activity in the cochlea of mice from postnatal days 7-10; if absent, mice are severely hearing impaired $(92,93)$. Dio2 mRNA is localized to structures that give rise to the bony labyrinth whereas T3 nuclear receptors are limited to the sensory epithelium, suggesting a paracrine pathway of $\mathrm{D} 2$-mediated $\mathrm{T} 3$ production and action in cochlear development.

The changes in deiodinase activity seen in the developing retina and cochlea are due to changes in Dio2 and Dio 3 transcription. In contrast, in the tibial growth plate of developing chickens, the critical regulatory events occur posttranslationally (28). In these animals, ubiquitination of D2, and thus thyroid hormone signaling, is under the control of the Hedgehog signaling cascade. In response to Hedgehog signaling, the D2-specific ubiquitin ligase WD repeat and SOCS box-containing 1 (WSB-1) is induced in perichondrial cells, thus accelerating D2 ubiquitination (Figure 4). The resulting decrease in D2 activity is thought to contribute to the Hedgehog induction of parathyroid hormone-related peptide (PTHrP). The link between D2 activity and PTHrP has been further substantiated by studies showing that pharmacologic acceleration of D2 ubiquitination via non-Hedgehog pathways also results in induction of this peptide (28).

By linking Hedgehog signaling with thyroid hormone action, WSB-1/D2 may play an important, previously unrecognized developmental role in cells or microenvironments where both Hedgehog and T3 have regulatory effects. For example, continuous Hedgehog signaling promotes the proliferation of oligodendrocyte precursor cells (94) whereas T3 favors differentiation of these cells $(95,96)$. Because astrocytes are known to respond to Hedgehog and to have D2 activity $(97,98)$, one mechanism for the proliferative effect of Hedgehog could be WSB-1-mediated downregulation of astrocyte $\mathrm{T} 3$ production, which would help sustain a microenvironment of relative hypothyroidism. On the other hand, WSB-1 may play a homeostatic role in some settings, for example, in X. laevis intestine during metamorphosis, where D2 is expressed and Hedgehog signaling is induced by T3 (99). In this case, a negative feedback loop could exist where WSB-1-mediated D2 ubiquitination could be induced as a result of D2-catalyzed T4-to-T3 conversion.

\section{Final remarks}

From a broad perspective, deiodination of iodothyronines can be seen as an example of a paradigm in which hormones are activated or inactivated in a controlled fashion in specific extraglandular tissues. The deiodinases thus play a role analogous to that of $5 \alpha$-reductase and $\mathrm{P} 450$ aromatase in sex steroid metabolism and of $11 \beta$-hydroxysteroid dehydrogenase in glucocorticoid metabolism. The breadth of actions of these enzymes are only now being recognized; compared with the situation with the steroid metabolizing enzymes, for which multiple antagonist drugs are in widespread clinical use, drug development for the control of deiodination is in its infancy.

The therapeutic potential is both obvious and intriguing: if the D2 pathway can be harnessed pharmacologically, the resulting control of energy expenditure may be useful in the treatment of obesity, type 2 diabetes, and the metabolic syndrome.

\section{Acknowledgments}

We thank our colleagues Robert D. Utiger, for his comments on the manuscript, and P. Reed Larsen, for his support. The authors receive support from the NIH (DK58538, DK65055, and DK64643).

Address correspondence to: Antonio C. Bianco, Division of Endocrinology, Diabetes and Hypertension, Brigham and Women's Hospital, 77 Avenue Louis Pasteur, HIM Building, Room 643, Boston, Massachusetts 02115, USA. Phone: (617) 525-5153; Fax: (617) 731-4718; E-mail: abianco@partners.org.
1. Wu, Y., and Koenig, R.J. 2000. Gene regulation by thyroid hormone. Trends Endocrinol. Metab. 11:207-211.

2. Wondisford, F.E. 2003. Thyroid hormone action: insight from transgenic mouse models. J. Investig. Med. 51:215-220.

3. Yen, P.M., et al. 2006. Thyroid hormone action at the cellular, genomic and target gene levels. Mol. Cell. Endocrinol. 246:121-127.

4. St. Germain, D.L., and Galton, V.A. 1997. The deio- dinase family of selenoproteins. Thyroid. 7:655-668. 5. Bianco, A.C., Salvatore, D., Gereben, B., Berry, M.J., and Larsen, P.R. 2002. Biochemistry, cellular and molecular biology and physiological roles of the iodothyronine selenodeiodinases. Endocr. Rev. 23:38-89.

6. Kohrle, J., Jakob, F., Contempre, B., and Dumont, J.E. 2005. Selenium, the thyroid, and the endocrine system. Endocr. Rev. 26:944-984.
7. Bianco, A.C., and Larsen, P.R. 2005. Cellular and structural biology of the deiodinases. Thyroid. 15:777-786.

8. Leonard, J.L., Visser, T.J., and Leonard, D.M. 2001. Characterization of the subunit structure of the catalytically active type I iodothyronine deiodinase. J. Biol. Chem. 276:2600-2607.

9. Callebaut, I., et al. 2003. The iodothyronine selenodeiodinases are thioredoxin-fold family proteins 
containing a glycoside hydrolase-clan GH-A-like structure. J. Biol. Chem. 278:36887-36896.

10. Curcio-Morelli, C., et al. 2003. In vivo dimerization of types 1,2, and 3 iodothyronine selenodeiodinases. Endocrinology. 144:937-946.

11. Kuiper, G.G., Kester, M.H., Peeters, R.P., and Visser, T.J. 2005. Biochemical mechanisms of thyroid hormone deiodination. Thyroid. 15:787-798.

12. Jansen, J., Friesema, E.C., Milici, C., and Visser, T.J. 2005. Thyroid hormone transporters in health and disease. Thyroid. 15:757-768.

13. Oppenheimer, J.H. 1979. Thyroid hormone action at the cellular level. Science. 203:971-979.

14. Larsen, P.R., Silva, J.E., and Kaplan, M.M. 1981. Relationships between circulating and intracellular thyroid hormones: physiological and clinical implications. Endocr. Rev. 2:87-102.

15. Bianco, A.C., and Silva, J.E. 1987. Nuclear 3,5,3'triiiodothyronine (T3) in brown adipose tissue: receptor occupancy and sources of $\mathrm{T} 3$ as determined by in vivo techniques. Endocrinology. 120:55-62.

16. Peeters, R.P., Debaveye, Y., Fliers, E., and Visser, T.J. 2006. Changes within the thyroid axis during critical illness. Crit. Care Clin. 22:41-55.

17. Martino, E., Bartalena, L., Bogazzi, F., and Braverman, L.E. 2001. The effects of amiodarone on the thyroid. Endocr. Rev. 22:240-254

18. Huang, S.A., et al. 2000. Severe hypothyroidism caused by type 3 iodothyronine deiodinase in infantile hemangiomas. N. Engl. J. Med. 343:185-189.

19. Huang, S.A., et al. 2002. A 21-year-old woman with consumptive hypothyroidism due to a vascular tumor expressing type 3 iodothyronine deiodinase. J. Clin. Endocrinol. Metab. 87:4457-4461.

20. Huang, S.A., Dorfman, D.M., Genest, D.R., Salvatore, D., and Larsen, P.R. 2003. Type 3 iodothyronine deiodinase is highly expressed in the human uteroplacental unit and in fetal epithelium. J. Clin. Endocrinol. Metab. 88:1384-1388.

21. Wasco, E.C., et al. 2003. Determinants of iodothyronine deiodinase activities in rodent uterus. Endocrinology. 144:4253-4261.

22. Alexander, E.K., et al. 2004. Timing and magnitude of increases in levothyroxine requirements during pregnancy in women with hypothyroidism. N. Engl J. Med. 351:241-249.

23. Peeters, R.P., et al. 2005. A polymorphism in type I deiodinase is associated with circulating free insulin-like growth factor I levels and body composition in humans. J. Clin. Endocrinol. Metab. 90:256-263.

24. Peeters, R.P., et al. 2005. A new polymorphism in the type II deiodinase gene is associated with circulating thyroid hormone parameters. Am. J. Physiol. Endocrinol. Metab. 289:E75-E81.

25. Appelhof, B.C., et al. 2005. Polymorphisms in type 2 deiodinase are not associated with well-being, neurocognitive functioning, and preference for combined thyroxine $/ 3,5,3^{\prime}$-triiodothyronine therapy. J. Clin. Endocrinol. Metab. 90:6296-6299.

26. Peeters, R.P., et al. 2003. Polymorphisms in thyroid hormone pathway genes are associated with plasma TSH and iodothyronine levels in healthy subjects. J. Clin. Endocrinol. Metab. 88:2880-2888.

27. Mentuccia, D., et al. 2002. Association between a novel variant of the human type 2 deiodinase gene Thr92Ala and insulin resistance: evidence of interaction with the Trp64Arg variant of the beta3-adrenergic receptor. Diabetes. 51:880-883.

28. Dentice, M., et al. 2005. The Hedgehog-inducible ubiquitin ligase subunit WSB-1 modulates thyroid hormone activation and PTHrP secretion in the developing growth plate. Nat. Cell Biol. 7:698-705.

29. Watanabe, M., et al. 2006. Bile acids induce energy expenditure by promoting intracellular thyroid hormone activation. Nature. 439:484-489.

30. Schimmel, M., and Utiger, R.D. 1977. Thyroidal and peripheral production of thyroid hormones. Review of recent findings and their clinical implications.
Ann. Intern. Med. 87:760-768.

31. Geffner, D.L., Azukizawa, M., and Hershman, J.M 1975. Propylthiouracil blocks extrathyroidal conversion of thyroxine to triiodothyronine and augments thyrotropin secretion in man. J. Clin. Invest. 55:224-229.

32. Saberi, M., Sterling, F.H., and Utiger, R.D. 1975 Reduction in extrathyroidal triiodothyronine production by propylthiouracil in man. J. Clin. Invest. 55:218-223.

33. Maia, A.L., Kim, B.W., Huang, S.A., Harney, J.W., and Larsen, P.R. 2005. Type 2 iodothyronine deiodinase is the major source of plasma T3 in euthyroid humans. J. Clin. Invest. 115:2524-2533. doi:10.1172/JCI25083.

34. Abuid, J., and Larsen, P.R. 1974. Triiodothyronine and thyroxine in hyperthyroidism. Comparison of the acute changes during therapy with antithyroid agents. J. Clin. Invest. 54:201-208.

35. Zavacki, A.M., et al. 2005. Type 1 iodothyronine deiodinase is a sensitive marker of peripheral thyroid status in the mouse. Endocrinology. 146:1568-1575.

36. Gereben, B., Goncalves, C., Harney, J.W., Larsen, P.R., and Bianco, A.C. 2000. Selective proteolysis of human type 2 deiodinase: a novel ubiquitin-proteasomal mediated mechanism for regulation of hormone activation. Mol. Endocrinol. 14:1697-1708.

37. Steinsapir, J., Harney, J., and Larsen, P.R. 1998. Type 2 iodothyronine deiodinase in rat pituitary tumor cells is inactivated in proteasomes. J. Clin. Invest. 102:1895-1899.

38. Curcio-Morelli, C., et al. 2003. Deubiquitination of type 2 iodothyronine deiodinase by pVHL-interacting deubiquitinating enzymes regulates thyroid hormone activation. J. Clin. Invest. 112:189-196. doi:10.1172/JCI200318348

39. St. Germain, D.L., Hernandez, A., Schneider, M.J., and Galton, V.A. 2005. Insights into the role of deiodinases from studies of genetically modified animals. Thyroid. 15:905-916.

40. Schneider, M.J., et al. 2006. Targeted disruption of the type 1 selenodeiodinase gene (dio1) results in marked changes in thyroid hormone economy in mice. Endocrinology. 147:580-589.

41. Schneider, M.J., et al. 2001. Targeted disruption of the type 2 selenodeiodinase gene (Dio2) results in a phenotype of pituitary resistance to T4. Mol. Endocrinol. 15:2137-2148.

42. Berry, M.J., et al. 1993. Physiological and genetic analyses of inbred mouse strains with a type I iodothyronine $5^{\prime}$ deiodinase deficiency. J. Clin. Invest. 92:1517-1528

43. Schoenmakers, C.H.H., Pigmans, I.G.A.J., Poland, A., and Visser, T.J. 1993. Impairement of the selenoenzyme type I iodothyronine deiodinase in $\mathrm{C} 3 \mathrm{H} /$ He mice. Endocrinology. 132:357-361.

44. Christoffolete, M.A., et al. 2006. Mice with combined targeted disruption of the Dio2 gene and a type 1 deiodinase deficient background maintain euthyroid serum T3 levels and are susceptible to diet induced obesity. In Annual Meeting of the Endocrine Society. June 24-27. Boston, Massachusetts, USA. http://www.abstracts2view.com/endo/.

45. Silva, J.E., and Larsen, P.R. 1977. Pituitary nuclear $3,5,3^{\prime}$-triiodothyronine and thyrotropin secretion: an explanation for the effect of thyroxine. Science. 198:617-620

46. Christoffolete, M.A., et al. 2006. Atypical expression of type 2 iodothyronine deiodinase in thyrotrophs explains the thyroxine-mediated pituitary TSH feedback mechanism. Endocrinology. 147:1735-1743.

47. Obregon, M.J., Escobar del Rey, F., and Morreale de Escobar, G. 2005. The effects of iodine deficiency on thyroid hormone deiodination. Thyroid. 15:917-929.

48. Dumitrescu, A.M., et al. 2005. Mutations in SECISBP2 result in abnormal thyroid hormone metabolism. Nat. Genet. 37:1247-1252.

49. Faber, J., and Siersbaek-Nielsen, K. 1996. Serum free 3,5,3'-triiodothyronine (T3) in non-thyroidal somatic illness, as measured by ultrafiltration and immunoextraction. Clin. Chim. Acta. 256:115-123.

50. Chopra, I.J. 1998. Simultaneous measurement of free thyroxine and free 3,5, $3^{\prime}$-triiodothyronine in undiluted serum by direct equilibrium dialysis/ radioimmunoassay: evidence that free triiodothyronine and free thyroxine are normal in many patients with the low triiodothyronine syndrome. Thyroid. 8:249-257.

51. Kaplan, M.M., et al. 1982. Prevalence of abnormal thyroid function test results in patients with acute medical illnesses. Am. J. Med. 72:9-16.

52. De Groot, L.J. 1999. Dangerous dogmas in medicine: the nonthyroidal illness syndrome. J. Clin. Endocrinol. Metab. 84:151-164.

53. Koenig, R.J. 2005. Regulation of type 1 iodothyronine deiodinase in health and disease. Thyroid. 15:835-840.

54. Kinlaw, W.B., Schwartz, H.L., and Oppenheimer, J.H. 1985. Decreased serum triiodothyronine in starving rats is due primarily to diminished thyroidal secretion of thyroxine. J. Clin. Invest. 75:1238-1241.

55. Peeters, R.P., et al. 2003. Reduced activation and increased inactivation of thyroid hormone in tissues of critically ill patients. J. Clin. Endocrinol. Metab. 88:3202-3211.

56. De Groot, L.J. 2006. Non-thyroidal illness syndrome is a manifestation of hypothalamic-pituitary dysfunction, and in view of current evidence, should be treated with appropriate replacement therapies. Crit. Care Clin. 22:57-86.

57. Van den Berghe, G., et al. 1998. Neuroendocrinology of prolonged critical illness: effects of exogenous thyrotropin-releasing hormone and its combination with growth hormone secretagogues. J. Clin. Endocrinol. Metab. 83:309-319.

58. Cavalieri, R.R. 1991. The effects of nonthyroid disease and drugs on thyroid function tests. Med.Clin. North Am. 75:27-39.

59. Legradi, G., Emerson, C.H., Ahima, R.S., Flier, J.S., and Lechan, R.M. 1997. Leptin prevents fastinginduced suppression of prothyrotropin-releasing hormone messenger ribonucleic acid in neurons of the hypothalamic paraventricular nucleus. Endocrinology. 138:2569-2576.

60. Chan, J.L., Heist, K., DePaoli, A.M., Veldhuis, J.D., and Mantzoros, C.S. 2003. The role of falling leptin levels in the neuroendocrine and metabolic adaptation to short-term starvation in healthy men. J. Clin. Invest. 111:1409-1421. doi:10.1172/ JCI200317490

61. Fekete, C., et al. 2004. Lipopolysaccharide induces type 2 iodothyronine deiodinase in the mediobasal hypothalamus: implications for the nonthyroidal illness syndrome. Endocrinology. 145:1649-1655.

62. Zeold, A., et al. 2006. Characterization of the NF-kappaB responsiveness of the human dio2 gene. Endocrinology. 147:4419-4429.

63. Lowell, B.B., and Spiegelman, B.M. 2000. Towards a molecular understanding of adaptive thermogenesis. Nature. 404:652-660.

64. Bianco, A.C., and Silva, J.E. 1987. Intracellular conversion of thyroxine to triiodothyronine is required for the optimal thermogenic function of brown adipose tissue. J. Clin. Invest. 79:295-300.

65. Bianco, A.C., and Silva, J.E. 1988. Cold exposure rapidly induces virtual saturation of brown adipose tissue nuclear T3 receptors. Am. J. Physiol. 255:E496-E503.

66. De Jesus, L.A., et al. 2001. The type 2 iodothyronine deiodinase is essential for adaptive thermogenesis in brown adipose tissue. J. Clin. Invest. 108:1379-1385. doi:10.1172/JCI200113803.

67. Christoffolete, M.A., et al. 2004. Mice with targeted 
disruption of the Dio2 gene have cold-induced overexpression of uncoupling protein 1 gene but fail to increase brown adipose tissue lipogenesis and adaptive thermogenesis. Diabetes. 53:577-584.

68. Liu, X., et al. 2003. Paradoxical resistance to dietinduced obesity in UCP1-deficient mice. J. Clin. Invest. 111:399-407. doi:10.1172/JCI200315737.

69. Kalaany, N.Y., et al. 2005. LXRx regulate the balance between fat storage and oxidation. Cell Metab. 1:231-244.

70. Hull, D. 1977. Brown adipose tissue and the newborn infant's response to cold. In Scientific foundations of obstetrics and gynaecology. E.E. Philipp, J. Barnes, and M. Newton, editors. William Heinemann. London, United Kingdom. 545-550.

71. Houstek, J., et al. 1993. Type II iodothyronine 5'deiodinase and uncoupling protein in brown adipose tissue of human newborns. J. Clin. Endocrinol. Metab. 77:382-387.

72. Heaton, J.M. 1972. The distribution of brown adipose tissue in the human. J. Anat. 112:35-39.

73. Ricquier, D., Nechad, M., and Mory, G. 1982. Ultrastructural and biochemical characterization of human brown adipose tissue in pheochromocytoma. J. Clin. Endocrinol. Metab. 54:803-807.

74. Cohade, C., Mourtzikos, K.A., and Wahl, R.L. 2003. "USA-Fat": prevalence is related to ambient outdoor temperature-evaluation with 18F-FDG PET/CT. J. Nucl. Med. 44:1267-1270.

75. Hany, T.F., et al. 2002. Brown adipose tissue: a factor to consider in symmetrical tracer uptake in the neck and upper chest region. Eur. J. Nucl. Med. Mol. Imaging. 29:1393-1398.

76. Garcia, C.A., et al. 2006. Reduction of brown fat 2-deoxy-2-[F-18]fluoro-D-glucose uptake by controlling environmental temperature prior to positron emission tomography scan. Mol. Imaging Biol. 8:24-29.

77. Silva, J.E. 2005. Thyroid hormone and the energetic cost of keeping body temperature. Biosci. Rep. 25:129-148.

78. Lebon, V., et al. 2001. Effect of triiodothyronine on mitochondrial energy coupling in human skeletal muscle. J. Clin. Invest. 108:733-737. doi:10.1172/
JCI200111775.

79. Harper, M.E., and Brand, M.D. 1993. The quantitative contributions of mitochondrial proton leak and ATP turnover reactions to the changed respiration rates of hepatocytes from rats of different thyroid status. J. Biol. Chem. 268:14850-14860.

80. Desai-Yajnik, V., Zeng, J., Omori, K., Sherman, J., and Morimoto, T. 1995. The effect of thyroid hormone treatment on the gene expression and enzyme activity of rat liver sodium-potassium dependent adenosine triphosphatase. Endocrinology. 136:629-639.

81. Folke, M., and Sestoft, L. 1977. Thyroid calorigenesis in isolated, perfused rat liver: minor role of active sodium-potassium transport. J. Physiol. 269:407-419.

82. De Meis, L. 2001. Role of the sarcoplasmic reticulum Ca2+-ATPase on heat production and thermogenesis. Biosci. Rep. 21:113-137.

83. Reis, M., Farage, M., and de Meis, L. 2002. Thermogenesis and energy expenditure: control of heat production by the $\mathrm{Ca}(2+)$-ATPase of fast and slow muscle. Mol. Membr. Biol. 19:301-310.

84. Izumo, S., Nadal-Ginard, B., and Mahdavi, V. 1986. All members of the MHC multigene family respond to thyroid hormone in a highly tissue-specific manner. Science. 231:597-600.

85. Simonides, W.S., Thelen, M.H., van der Linden, C.G., Muller, A., and van Hardeveld, C. 2001. Mechanism of thyroid-hormone regulated expression of the SERCA genes in skeletal muscle: implications for thermogenesis. Biosi. Rep. 21:139-154.

86. Oppenheimer, J.H., Schwartz, H.L., Lane, J.T., and Thompson, M.P. 1991. Functional relationship of thyroid hormone-induced lipogenesis, lipolysis, and thermogenesis. J. Clin. Invest. 87:125-132.

87. Galton, V.A. 2005. The roles of the iodothyronine deiodinases in mammalian development. Thyroid. 15:823-834.

88. Brown, D.D. 2005. The role of deiodinases in amphibian metamorphosis. Thyroid. 15:815-821.

89. Marsh-Armstrong, N., Huang, H., Remo, B.F., Liu, T.T., and Brown, D.D. 1999. Asymmetric growth and development of the Xenopus laevis retina during metamorphosis is controlled by type III deiodinase. Neuron. 24:871-878.

90. Hernandez, A., Martinez, M.E., Fiering, S., Galton, V.A., and St. Germain, D. 2006. Type 3 deiodinase is critical for the maturation and function of the thyroid axis. J. Clin. Invest. 116:476-484. doi:10.1172/ JCI26240.

91. Huang, S.A., et al. 2005. TGF-B promotes inactivation of extracellular thyroid hormones via transcriptional stimulation of type 3 iodothyronine deiodinase. Mol. Endocrinol. 19:3126-3136.

92. $\mathrm{Ng}$, L., et al. 2004. Hearing loss and retarded cochlear development in mice lacking type 2 iodothyronine deiodinase. Proc. Natl. Acad. Sci. U. S. A. 101:3474-3479.

93. Campos-Barros, A., et al. 2000. Type 2 iodothyronine deiodinase expression in the cochlea before the onset of hearing. Proc. Natl. Acad. Sci. U. S. A. 97:1287-1292.

94. Billon, N., Jolicoeur, C., Ying, Q.L., Smith, A., and Raff, M. 2002. Normal timing of oligodendrocyte development from genetically engineered, lineage-selectable mouse ES cells. J. Cell Sci. 115:3657-3665.

95. Barres, B.A., Lazar, M.A., and Raff, M.C. 1994. A novel role for thyroid hormone, glucocorticoids and retinoic acid in timing oligodendrocyte development. Development. 120:1097-1108.

96. Billon, N., Tokumoto, Y., Forrest, D., and Raff, M. 2001. Role of thyroid hormone receptors in timing oligodendrocyte differentiation. Dev. Biol. 235:110-120.

97. Guadano-Ferraz, A., Obregon, M.J., St. Germain, D.L., and Bernal, J. 1997. The type 2 iodothyronine deiodinase is expressed primarily in glial cells in the neonatal rat brain. Proc. Natl. Acad. Sci. U. S. A. 94:10391-10396.

98. Wallace, V.A., and Raff, M.C. 1999. A role for Sonic hedgehog in axon-to-astrocyte signalling in the rodent optic nerve. Development. 126:2901-2909.

99. Stolow, M.A., and Shi, Y.B. 1995. Xenopus sonic hedgehog as a potential morphogen during embryogenesis and thyroid hormone-dependent metamorphosis. Nucleic Acids Res. 23:2555-2562. 